\title{
Immunohistological study of oestrogen receptors in breast carcinomas that are biochemically receptor negative
}

\author{
S Shousha, T Stamp, K R James, J Alaghband-Zadeh
}

\begin{abstract}
The reliability of an immunohistological method, applied to paraffin wax sections, was assessed for determination of oestrogen receptor content of biochemically oestrogen receptor negative breast carcinomata. Sixty consecutive tumours with oestrogen receptor concentrations of less than $10 \mathrm{fmol} / \mathrm{mg}$ cytosol protein, as estimated by dextran-coated charcoal biochemical assay, were examined. Paraffin wax sections were treated with DNAse before applying a peroxidaseanti-peroxidase method using ER-ICA monoclonal antibodies. Fifty one cases $(85 \%)$ were negative, six $(10 \%)$ weakly positive, and three $(5 \%)$ were moderately positive. No strongly positive cases were seen.

It is suggested that cases with weakly positive staining, especially when localised to a small area, should be regarded as negative. On the other hand, as the three moderately stained cases included two small tubular carcinomas and an invasive ductal carcinoma with high progesterone receptor concentrations, it is more likely that the biochemiccal assay in these cases represented false negative results due to sampling error or inclusion of fibrous or other non-neoplastic tissue in the assayed samples. It is concluded that the immunohistological method used here is fairly reliable and would be especially valuable for determination of oestrogen receptor content in small, mammographically detected tumours from which no tissue would be available for biochemical assay or frozen section examination.
\end{abstract}

Department of

Histopathology,

Charing Cross and

Westminster Medical

School, London

S Shousha

T Stamp

K R James

Department of

Chemical Pathology

$\mathrm{J}$ Alaghband-Zadeh

Correspondence to:

Dr S Shousha, Departmen of Histopathology, Charing Cross Hospital, Fulham Palace Road, London

W6 8RF, England.

Accepted for publication 19 October 1989
The recent introduction of immunohistological methods for the detection of oestrogen receptors in paraffin wax sections provides a much needed facility for examination of routinely processed histological material. ${ }^{1-3}$ Recently, we assessed the use of one of these methods in a study of 19 cases of mucinous breast carcinoma, a tumour known to be rich in oestrogen receptor content. We found the results consistent with those obtained by the standard dextran-coated charcoal biochemical assay in the cases examined by both methods. ${ }^{4}$ The current study was aimed at assessing the same immunohistological method in a large series of breast carcinomas found to be oestrogen receptor negative by the biochemical assay.

\section{Methods}

The study included 60 consecutive cases of breast carcinoma with oestrogen receptor concentrations of less than $10 \mathrm{fmol} / \mathrm{mg}$ cytosol protein, as estimated by the dextran-coated charcoal biochemical assay. ${ }^{5}$ All tumours were removed surgically at Charing Cross Hospital between 1979-1982. The original haematoxylin and eosin stained sections were reviewed and a representative section of each case was selected. Sections $5 \mu$ m thick were cut from the corresponding formalin fixed, paraffin wax embedded blocks of tumour tissue and used for the immunohistological study.

As previously described ${ }^{4}$ the sections were dewaxed, hydrated through graded alcohols, and rinsed in TRIS buffer ( $\mathrm{pH}$ 7.6). Endogenous peroxidase activity was blocked by using $0.5 \%$ hydrogen peroxide in methanol for 10 minutes. The method described by Shintaku and Said for the demonstration of oestrogen receptors in paraffin wax sections ${ }^{1}$ was then applied. The sections were covered with DNAse I (Sigma D5025) solution in a moist chamber for two hours. The concentration of the DNAse solution was decided by titrating against a known oestrogen receptor positive control case, using doubling dilutions from $40 \mathrm{mg}$ to $5 \mathrm{mg}$ per $\mathrm{ml}$ of $0.01 \mathrm{M}$ magnesium sulphate in TRIS buffer. It is essential to do this for each batch of DNAse as the enzyme activity may vary considerably. ${ }^{6}$ In this study the enzyme activity was 2200 Kunitz units per $\mathrm{mg}$ solid, and a dilution of $20 \mathrm{mg}$ per ml (44 000 Kunitz units per $\mathrm{ml}$ ) was found to be optimal.

The sections were then rinsed in TRIS buffered saline (TBS), covered for 30 minutes with normal goat serum, followed by overnight incubation in a moist chamber with several drops of ER-ICA monoclonal antibody (Abbott Laboratories England). After rinsing in TBS the sections were successively covered for two hours each with goat anti-rat immunoglobulin and rat peroxidase-anti-peroxidase complex. This was followed by rinsing in TBS, incubation in diaminobenzidine for $10 \mathrm{~min}$ utes, washing in tap water and light counterstaining with haematoxylin. A control slide from each case was treated similarly except for replacement of the specific antiserum with the negative control antibody supplied with the ER-ICA kit.

The staining results were assessed semiquantitatively according to the percentage of cells stained and the intensity of the staining, as previously described. ${ }^{4} \mathrm{~A}$ scale of $1-3$ was used for each of these two components. For the percentage of stained cells, 1 referred to stain- 
Table 1 Distribution of histological types of breast carcinoma with oestrogen receptor (number $(\%)$ ) concentrations of $<10 \mathrm{fmol} / \mathrm{mg}$ cytosol protein compared with carcinomas with concentrations of $\geqslant 10 \mathrm{fmol}$

\begin{tabular}{lcc}
\hline Histological type & $\begin{array}{c}<10 \mathrm{fmol} \\
(n=60)\end{array}$ & $\begin{array}{c}\geqslant 10 \mathrm{fmol} \\
(n=190)\end{array}$ \\
\hline Invasive ductal & $48(80 \cdot 0)$ & $146(76 \cdot 8)$ \\
Medullary & $7(11 \cdot 7)$ & $2(1 \cdot 1)$ \\
Tubular & $2(3 \cdot 3)$ & $2(1 \cdot 1)$ \\
Invasive lobular & $1(1 \cdot 7)$ & $37(19 \cdot 5)$ \\
Mucinous & $1(1 \cdot 7)$ & $1(0 \cdot 5)$ \\
Squamous & $1(1 \cdot 7)$ & 0 \\
Papillary & 0 & $2(1 \cdot 1)$ \\
\hline
\end{tabular}

ing of less than $33^{\circ}$ of tumour cells, 2 for 33 $66^{\circ}$, and 3 for the presence of more than $66 \%$ positively stained cells. For staining intensity, 1 indicated weak, 2 moderate, and 3 strong staining. The two factors were then multiplied by each other and the final result expressed as follows: - = negative (no staining); $+=$ weakly positive (for a total score of 1-3); $++=$ moderately positive (score 4-6); $++t=$ strongly positive (score of $>6$ ). The total score, when mentioned, was followed between parentheses by the two numbers representing its components. For example, a moderately positive case with a score of 6 $(3 \times 2)$ means that more than two thirds of its neoplastic cells showed oestrogen receptor staining of a moderate intensity, while a case with a score of $6(2 \times 3)$ means that about half its tumour cells were strongly stained.

The significance of the results was assessed by the fourfold tables of the $\chi^{2}$ test. Probabilities were calculated with one degree of freedom.

\section{Results}

The 60 tumours included $48(80 \%)$ invasive ductal carcinomas, seven $(11.7 \%$ ) medullary (three typical and four atypical), two (3.3\%) tubular, one $\left(1.7^{\circ}\right)$ each of invasive lobular, pure mucinous, and pure squamous cell carcinoma. Table 1 compares the distribution of histological types in these cases with that of 190 cases of breast carcinoma with oestrogen receptor concentrations of $10 \mathrm{fmol} / \mathrm{mg}$ cytosol protein or more, seen during the same period (1979-1982). The two main differences between the two groups were a significantly much higher incidence of medullary carcinoma $(\mathrm{p}<0.001)$ and a low incidence of invasive lobular carcinoma $(p<0.001)$ in the oestrogen receptor negative group.

The immunohistological brown positive staining, when present, was restricted to the nuclei of neoplastic cells and some non-neo-

Table 2 Immunohistological oestrogen receptor staining results according to histological type of tumour

\begin{tabular}{lrlll}
\hline Histological type & - & + & ++ & +++ \\
\hline Invasive ductal $(\mathrm{n}=48)$ & 42 & 5 & 1 & 0 \\
Medullary $(\mathrm{n}=7)$ & 6 & 1 & 0 & 0 \\
Tubular $(\mathrm{n}=2)$ & 0 & 0 & 2 & 0 \\
Invasive lobular $(\mathrm{n}=1)$ & 1 & 0 & 0 & 0 \\
Mucinous $(\mathrm{n}=1)$ & 1 & 0 & 0 & 0 \\
Squamous $(\mathrm{n}=1)$ & 1 & 0 & 0 & 0 \\
Total $(\mathrm{n}=60)$ & $51\left(85^{\circ}{ }_{0}\right)$ & $6\left(10^{\circ}{ }_{0}\right)$ & $3\left(5^{\circ}{ }_{0}\right)$ & 0 \\
\hline
\end{tabular}

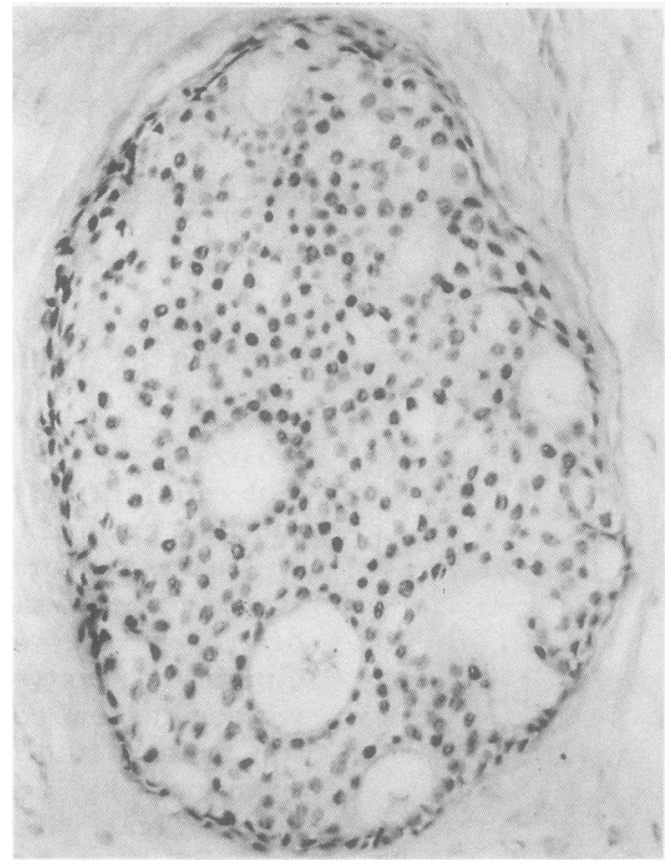

Figure 1 Intraduct cribriform carcinoma showing moderately positive staining for oestrogen receptors. (Immunoperoxidase.)

plastic epithelial cells. No cytoplasmic, stromal, or background staining was seen.

Fifty one tumours $(85 \%)$ were immunohistologically oestrogen receptor negative, six weakly positive, and three moderately positive. No strongly positive cases were seen. The distribution of the results according to histological type is shown in table 2 .

The weakly positive cases included five invasive ductal carcinomas and an atypical medullary carcinoma. The total score was 1 $(1 \times 1)$ in four of these tumours and $3(3 \times 1)$ in two. Three out of the six weakly positive cases contained foci of intraductal carcinoma and these were all positively stained for oestrogen receptor $(100 \%)$. In contrast, only one $(7 \%)$ out of 14 negatively stained invasive ductal carcinoma with intraductal elements showed positive staining of these elements. Most of the positively stained intraductal elements were of the solid and cribriform type (figure 1), and most of the negative ones were of the comedo type.

The three tumours with moderately positive oestrogen receptor staining included the only two pure tubular carcinomas included in this series and a well differentiated invasive ductal carcinoma. For the tubular carcinomas the total oestrogen receptor score was $4(2 \times 2)$ in one and $6(3 \times 2)$ in the other. The two tumours were of a small size, each measuring $1 \mathrm{~cm}$ in maximum dimension, and their neoplastic glands were widely separated by abundant fibrous tissue (figure 2). The second of these tumours had foci of solid intraductal carcinoma which were positively stained. The moderately stained ductal carcinoma had a score of $4(2 \times 2)$ and contained positively stained solid intraductal elements. It had a progesterone receptor concentration of $80 \mathrm{fmol} / \mathrm{mg}$ cytosol protein (assayed biochemically). No record of the size of this tumour was available. 


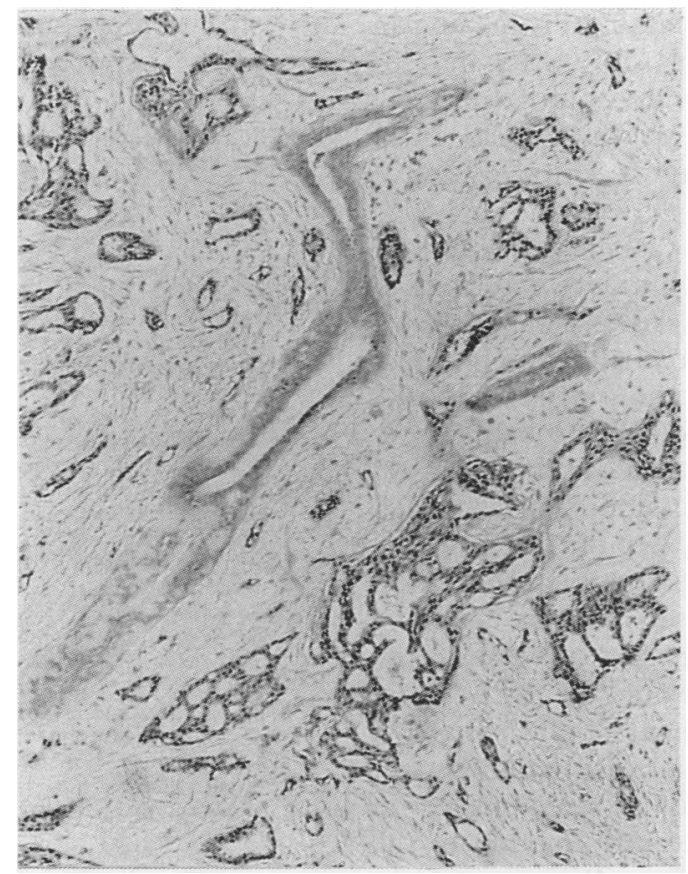

Figure 2 Tubular carcinoma of the breast. Malignant tubules show moderate staining for oestrogen receptors, while the normal ducts, seen here crossing the middle of the field, are oestrogen receptor negative.

(Immunoperoxidase.)

Although the invasive elements in the only lobular carcinoma included in this study were oestrogen receptor negative, the tumour contained foci of lobular carcinoma in situ which were faintly stained.

The results of progesterone receptor biochemical assay were available for eight out of nine immunohistologically oestrogen receptor weakly or moderately positive tumours and for all 51 oestrogen receptor negative tumours. Five $\left(62^{\circ}{ }_{0}\right)$ of the eight oestrogen receptor positive carcinomas, including two out of two moderate and three out of six weakly stained cases, were progesterone receptor positive ( $>10 \mathrm{fmol} / \mathrm{mg}$ cytosol protein; range: $11-80$; mean 30$)$, compared with eight $\left(16^{\circ} \%\right.$; range 11-46; mean 25) of the oestrogen receptor negative tumours. The difference in the incidence of progesterone receptor positivity between the two groups was significant $(p<0.01)$. When the results of the weakly $(\mathrm{n}=6)$ and moderately $(\mathrm{n}=2)$ progesterone receptor positive tumours were separated, the mean progesterone receptor concentration in the first group (11 fmol) was much lower than that of the second group ( $45 \mathrm{fmol}$ ). No statistical analysis was carried out because of the small size of the groups.

\section{Discussion}

In this study we concentrated on oestrogen receptor negative breast carcinoma, estimated biochemically, for two reasons. First, to assess the usefulness and reliability of the immunohistological method applied to routinely processed wax paraffin sections, for the determination of the oestrogen receptor content of such tumours; and secondly, to assess the possibility that in some tumours the negative oestrogen receptor biochemical assay may not be the result of real absence of receptors, but the result of the presence of a "diluting" factor like normal tissue in a small sized tumour or abundant fibrous tissue stroma in larger ones.

The results of the study show complete agreement between the chemical and histological methods in $85^{\circ}$ o of cases. This is similar to the results obtained by applying the immunohistological method to frozen sections of the tumours. ${ }^{78}$ In a further $10^{\circ}{ }_{0}$ of our cases in which the staining was only weakly positive the amount of receptors shown was probably insignificant, especially where the total score was 1 , reflecting a weak focal staining of a small part of the tumour, and even in cases with a score of $3(3 \times 1)$ where a more diffuse faint staining was seen. It may be more prudent, from a practical point of view, to regard these cases as negative, as suggested by the biochemical assay. This may not be the case with a score of $3(1 \times 3)$ where an intense staining would be present in a small part of the tumour, but we did not encounter such cases in this series.

The situation with the three cases which showed a moderately positive degree of staining is different. Here the staining was more intense and most cells stained. In at least two cases the tumours were of a small size and the neoplastic glands were widely separated from each other by abundant fibrous tissue. Biochemical assay for progesterone receptor was high $(80 \mathrm{fmol})$ in one tumour, low positive (11 fmol) in the second, and was not assayed in the third tumour because of the unavailability of tissue as a result of the small size of the lesion. All these factors would support considering these cases oestrogen receptor positive and the biochemical assay as representing a false negative result. A similar discrepancy between oestrogen receptor biochemical assay and immunohistological result has been observed previously in small tumours. ${ }^{78}$

The pattern of oestrogen receptor staining of in situ carcinoma noted in this study was basically similar to that previously reported by us in a series of mostly oestrogen receptor positive mucinous carcinomas. ${ }^{4}$ In particular, the staining of in situ elements tended to be similar to that of the associated invasive lesion. This was the case in all but two of the studied tumours which contained in situ malignant elements. The two exceptions were an oestrogen receptor negative invasive ductal tumour with positive solid and cribriform intraductal carcinoma and an oestrogen receptor negative invasive lobular tumour with positive foci of in situ lobular carcinoma. In general, most of the solid, cribriform, and papillary intraductal carcinomata showed varying degrees of positivity, while intraductal carcinoma of the comedo type was mostly negative.

It is concluded that the immunohistological method used in this study for the demonstration of oestrogen receptor in routinely processed paraffin wax sections can be reliably used for the determination of the oestrogen receptor content of negative as well as positive tumours. 
In particular, negative staining in this and in our previous study, ${ }^{4}$ was only seen in biochemically oestrogen receptor negative tumours. It seems, however, that a minority of biochemically oestrogen receptor negative tumours may show positive staining. The staining in most of these cases is weak, and for practical purposes these tumours may have to be considered negative, especially if the faint staining is localised to a small area. In small moderately stained tumours the results obtained with this method are probably more accurate than those obtained by biochemical assay, because of the possibility of sampling errors. The most critical step of the method is the determination of the suitable concentration of DNAse that can be used and this has to be decided by titration of each new batch of the enzyme. The method would be particularly valuable for the assessment of the oestrogen receptor content of the increasing numbers of small tumours likely to be encountered in clinical practice with the introduction of the National Breast Screening Programme. In many of these small tumours, or suspected tumours, no tissue will be available for biochemical assay and frozen section examination will be contraindicated. The whole lesion has to be examined thoroughly by paraffin wax sections, some of which can be used for assessment of oestrogen receptor content by this method, if and when it is needed.

This study was supported by a grant from the Peel Medical Research Trust.

1 Shintaku P, Said JW. Detection of estrogen receptors with monoclonal antibodies in routinely processed formalinfixed paraffin sections of breast carcinoma. Use of DNAse pretreatment to enhance sensitivity of the reaction. $\mathrm{Am} J$ Clin Pathol 1987;87:161-7.

2 Andersen J, Orntoft TF, Poulsen HS. Immunohistochemical demonstration of estrogen receptors (ER) in formalin-fixed, paraffin-embedded human breast cancer tissue by use of a monoclonal antibody to ER. J Histochem Cytochem 1988;36:1553-60.

3 Cheng L, Binder SW, Fu YS, Lewin KJ. Demonstration of estrogen receptors by monoclonal antibody in formalinfixed breast tumors. Lab Invest 1988;58:346-53.

4 Shousha S, Coady AT, Stamp T, James KR, AlaghbandZadeh J. Oestrogen receptors in mucinous carcinoma of the breast: an immunohistological study using paraffin wax sections. J Clin Pathol 1989;42:902-5.

5 King RJB, Redgrave S, Hayward JL, Millis RR, Rubens $R D$. The measurement of receptors for oestradiol and progesterone in human breast tumours. In: RJB King, Steroid receptor assays in human breast tumours. odological and clinical aspects. Cardiff: Alpha Omega, 1979:55-72.

6 Said J, Shintaku IP. Detection of estrogen receptors with monoclonal antibodies in paraffin sections. Am J Clin Pathol 1988;90:120.

7 Cudahy TJ, Boeryd BR, Franlund BK, Nordenskjold BA. A comparison of three different methods for the determination of estrogen receptors in human breast cancer. $\mathrm{Am}$ Clin Pathol 1988;90:583-90.

8 Hiort O, Kwan PWL, DeLellis RA. Immunohistochemistry of estrogen receptor protein in paraffin sections. Effects of enzymatic pretreatment and cobalt chloride intensification. Am J Clin Pathol 1988;90:559-63. 